\title{
High-temperature oxidation behavior of reaction-formed silicon carbide ceramics
}

\author{
Linus U. J.T. Ogbuji and M. Singh \\ NYMA, Inc., Lewis Rescarch Cemer Group, Cleveland, ohio 441.35
}

(Received 31 March 1995: accepted 7 August 1995)

The oxidation behavior of reaction-formed silicon carbide (RFSC) ceramics was investigated in the temperature range of 1100 to $1400{ }^{\circ} \mathrm{C}$. The oxidation weight change was recorded by TGA; the oxidized materials were examined by light and electron microscopy, and the oxidation product by $x$-ray diffraction analysis (XRD). The materials exhibited initial weight loss, followed by passive weight gain (with enhanced parabolic rates, $k_{i}$ ), and ending with a negative (logarithmic) deviation from the parabolic law. The weight loss arose from the oxidation of residual carbon, and the enhanced $k_{p}$, values from internal oxidation and the oxidation of residual silicon. while the logarithmic kinetics is thought to have resulted from crystallization of the oxide. The presence of a small amount of $\mathrm{MoSi}_{2}$ in the RFSC material caused a further increase in the oxidation rate. The only solid oxidation product for all temperatures studied was silica.

\section{INTRODUCTION}

Recently, there has been a surge of interest in the research and development of advanced silicon carbide ceramics intended for at variety of applications in aerospace, energy, nuclear, and automotive industries. ${ }^{1.2}$ The majority of these applications require components fabricated in net or near-net shapes at low cost. The fabrication of silicon carbide ceramics by reactive melt infiltration of silicon has some important advantages over the more conventional processes of pressureless sintering (PS), hot-pressing (HP), and chemical vapor deposition (CVD). These include full densification without external pressures and at much lower temperatures, and the potential for tailoring the product microstructure and composition by controlling the melt chemistry and engineering the preforms. Early attempts to exploit this technique utilized preforms of silicon carbide and graphitic carbon powders, and after silicon infiltration new silicon carbide grew epitaxially on silicon carbide seed crystals incorporated into the powder mix. ${ }^{3}$ Those reaction-sintered silicon carbides ("REFEL SiC", and their variants from other sources) often have a somewhat coarse and inhomogeneous microstructure characterized by significant porosity and a residue of unreacted phases.

A low cost technique for the processing of reactionformed silicon carbide (RFSC) ceramics has been recently developed, and the properties of a variety of RFSC materials have been reported. ${ }^{2.4}{ }^{8}$ In this process, silicon carbide ceramics are made by infiltrating molten silicon or silicon-( Mo, Nb) alloys into microporous carbon preforms (without seed crystals). ${ }^{+} 7$ The resulting $\beta-\mathrm{SiC}$ has a fine microstructure and excellent mechanical properties, which are only slightly degraded by exposure to elevated temperatures. ${ }^{8}$ There is no change of dimension during processing by this reactive infiltration technique. However, complete conversion of the carbon preform into silicon carbide without any residual phase is difficult, requiring a very delicate optimization of both the preform morphology (especially porosity and carbon strut size) and the infiltration conditions (particularly time, temperature, and the rate of infiltration).

It is well known that compositional and microstructural features can influence the oxidation kinetics of silicon-based ceramics, or the integrity of the resulting oxide. ${ }^{9.10}$ Residual silicon can influence the oxidation of RFSC ceramics in two ways. At the higher temperatures, the silicon (which melts at $1410^{\circ} \mathrm{C}$ ) will provide shortcircuit paths to oxidant diffusion in the same way that low-melting densification aids do in silica formers. 11.12 At intermediate temperatures, the higher oxidation rate of silicon (compared to $\mathrm{SiC}$ ) could result in an increase in the overall oxidation rate of the RFSC material. Unreacted carbon in RFSC would be expected to promote oxidation as well. The evolution of large amounts of $\mathrm{CO}$ or $\mathrm{CO}_{2}$ during oxidation will disrupt the protective silical scale, ${ }^{13}$ thus facilitating the ingress of oxidant. Also, internal oxidation down the skeletal networks of residual carbon could leave an inalogous network of porosity that would provide a conduit for the oxidant to the interior. Therefore, residual silicon and carbon in the RFSC materials might be deleterious to the excellent oxidation resistance of $\mathrm{SiC}$.

The purpose of this work was to study the isothermal oxidation behavior of reaction-formed silicon carbide (RFSC) ceramics from $1100{ }^{\circ} \mathrm{C}$ to $1400{ }^{\circ} \mathrm{C}$ in order to compare it, in terms of oxidation resistance, with $\mathrm{SiC}$ ceramics of different genesis. By including samples fabricated with and without molybdenum disili- 
cide phases, it was hoped to gain a first look at the role such second phases might play in the oxidation behavior of the material.

\section{EXPERIMENTAL PROCEDURE}

Two varieties of RFSC ceramic materials were investigated. One was made by melt-infiltration of pure silicon into microporous carbon preforms (and will be referred to as "basic RFSC" hereafter). The other was made by infiltration of a Si-3.2\% Mo alloy in a similar type of preform, resulting in a final product containing a small amount $(\sim 5 \%)$ of $\mathrm{MoSi}_{2}$. Both materials exhibited neartheoretical density but had second phases of residual silicon $(10 \% 1015 \%)$ as well as unreacted carbon. The fabrication details and characteristics of these materials have been described elsewhere. ${ }^{8}$ The microstructure of the samples before oxidation, which is shown in Fig. I for the basic material, was similar in both varieties (with and without $\mathrm{MoSi}_{2}$ ). The silicon carbide was tine grained, with a bimodal grain size distribution. A proper grain-size analysis was not undertaken, but the grain size was estimated from transmission electron microscopy (TEM) micrographs. The coarser grains were distributed around $2.0 \mu \mathrm{m}$, while the finer grains ranged from approximately 200 to $600 \mathrm{~nm}$.

The samples were cut into coupons, $1.0 \times 25 \times$ $38 \mathrm{~mm}$, and polished on both sides with a sequence of diamond abrasive to a mirror. Each coupon was separately oxidized in desiccant-dried bottled oxygen that flowed at $100 \mathrm{sccm}$ in a thermogravimetric analyzer (TGA) fitted with a Cahn-1000 microbalance and a highpurity alumina furnace tube. Oxidation was conducted at preset intervals of $50{ }^{\circ} \mathrm{C}$ in the range of $1100{ }^{\circ} \mathrm{C}$ to $1400{ }^{\circ} \mathrm{C}$, and for durations of $50 \mathrm{~h}$ in each case. Except in a few cases, each oxidation run was repeated to check reproducibility of data. Upon completion of each oxidation cycle, the sample was repolished and inspected by both light microscopy and scanning electron microscopy (SEM). Additionally, those low-lemperature samples with spotty oxide coverage were examined by elemental dot-mapping in SEM, while the thicker oxides grown at the higher temperatures were characterized by X-Ray Diffractometry (XRD). Particular attention was paid to ascertaining whether or not second phases (such as Mo oxides) were present in the oxide scales.

\section{RESULTS}

\section{A. Sample microstructure}

Figure I shows the microstructure of the unoxidized RFSC material. (The material containing a little $\mathrm{MoSi}_{2}$ had a very similar microstructure.) The gray background is silicon carbide and the light areas are residual silicon, while the dark patches are unreacted carbon of the preform. This micrograph shows that there was minimal

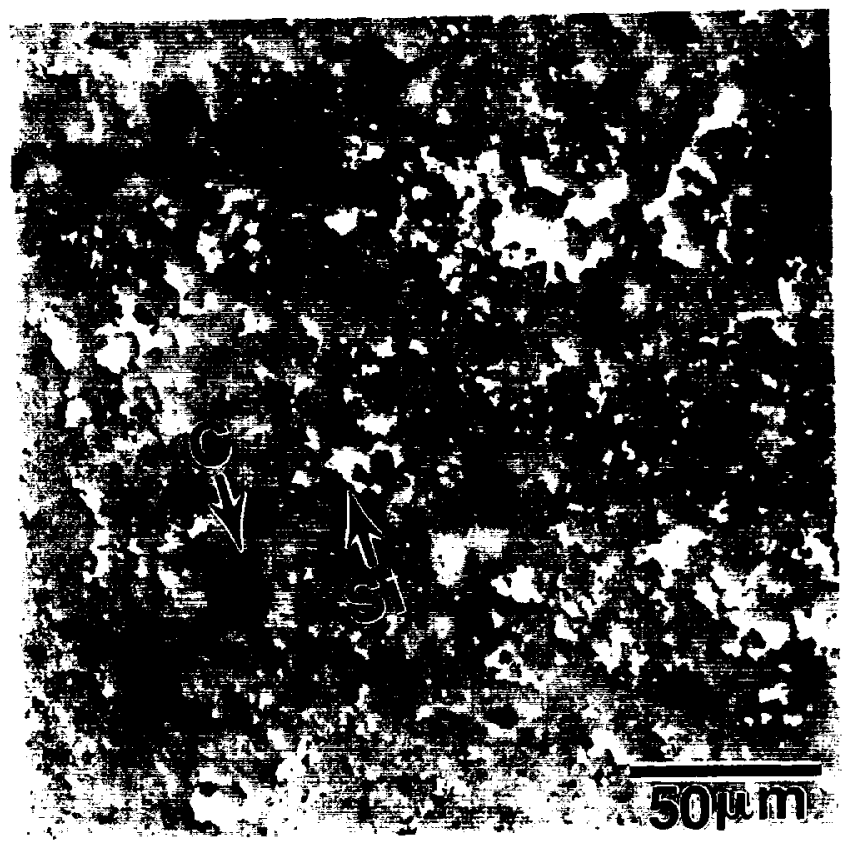

(a)

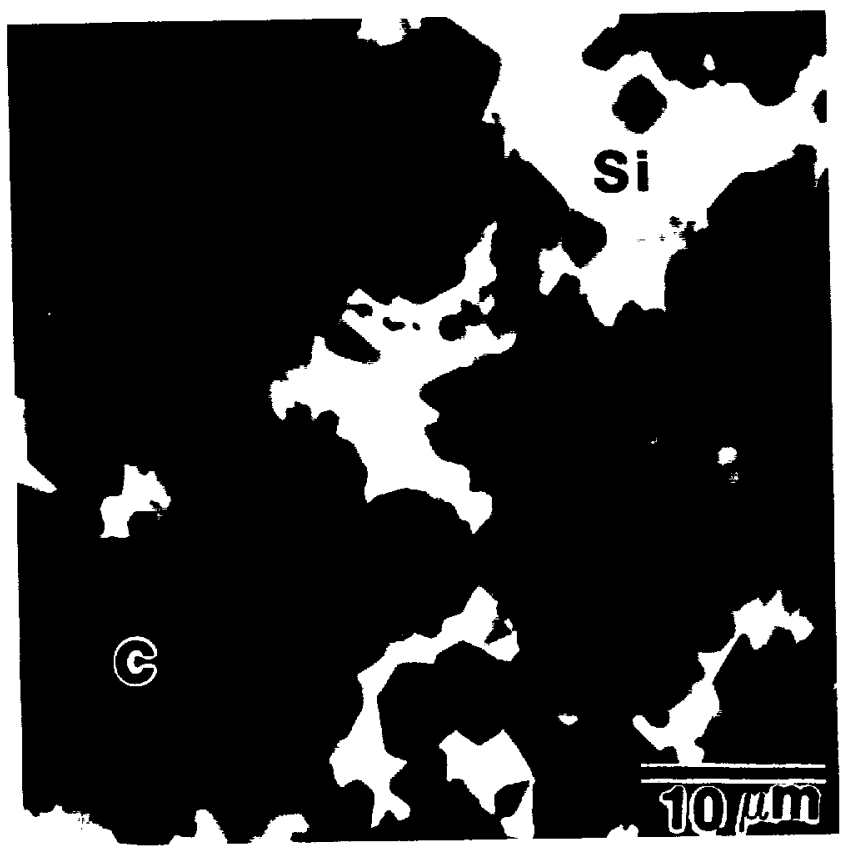

(b)

FIG. I. Microstructure of RFSC ceramics, showing residual silicon and carbon from the precursor: (a) light micrograph, as-fabricated material: (b) SEM. from unoxidized interior. after $50 \mathrm{~h} \mathrm{O}_{2}$ at $1150^{\circ} \mathrm{C}$.

porosity in the materials. In contrast. Figures 2 and 3 show SEM micrographs of polished sections of the two varieties after oxidation. Figure 2 shows the basic material oxidized at $1150{ }^{\circ} \mathrm{C}$, while Fig. 3 shows the variety with $\mathrm{MoSi} i_{2}$ after oxidation at $1350{ }^{\circ} \mathrm{C}$. The most prominent feature in Figs. 2 and 3 is oxidation-induced porosity. The pores appeared to be associated with 


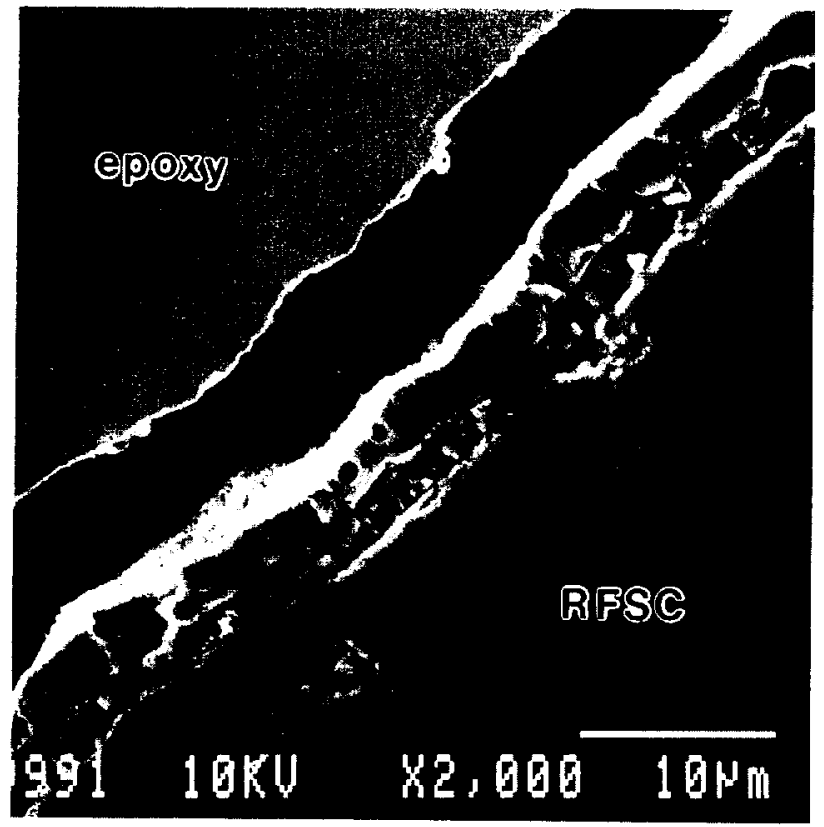

(a)

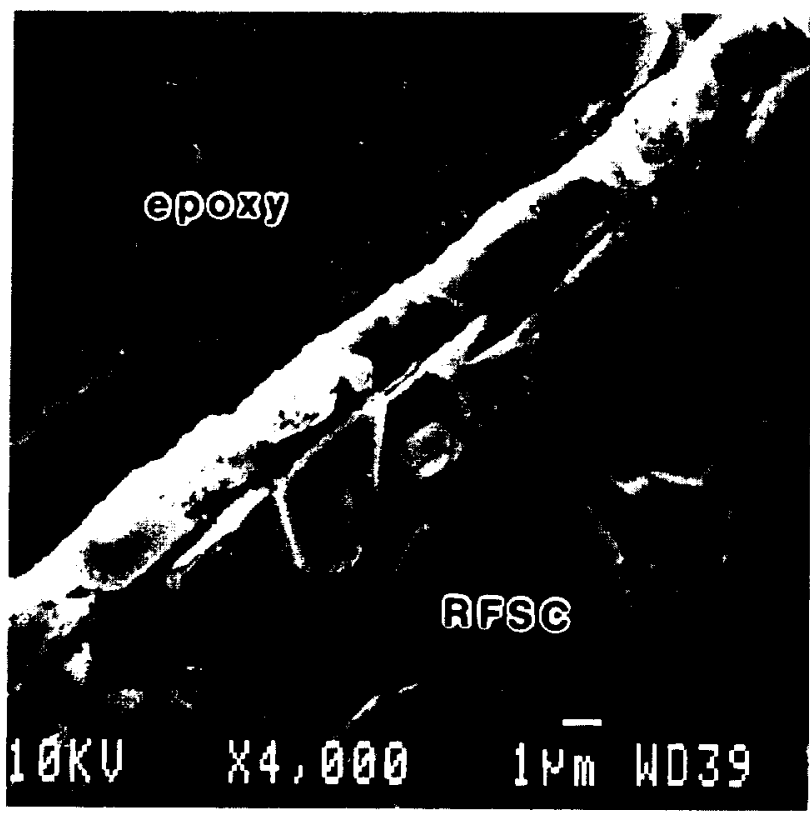

(b)

FIG. 2. SEM micrographs of the hasic RFSC oxidized at $1200{ }^{\circ} \mathrm{C}$. Although some isolated paltches remained free of porosity (a). the substrate became mostly porous just beneath the oxide scale (b).

the patches of residual carbon, reflecting their genesis in the burn off of the carbon. Most of the porosity occurred in a band of the substrate just under the oxide scales, but significant porosity was sometimes found at depths of up to $70 \mu \mathrm{m}$ beneath the oxide scale. The depth of penetration of the oxidation-induced porosity

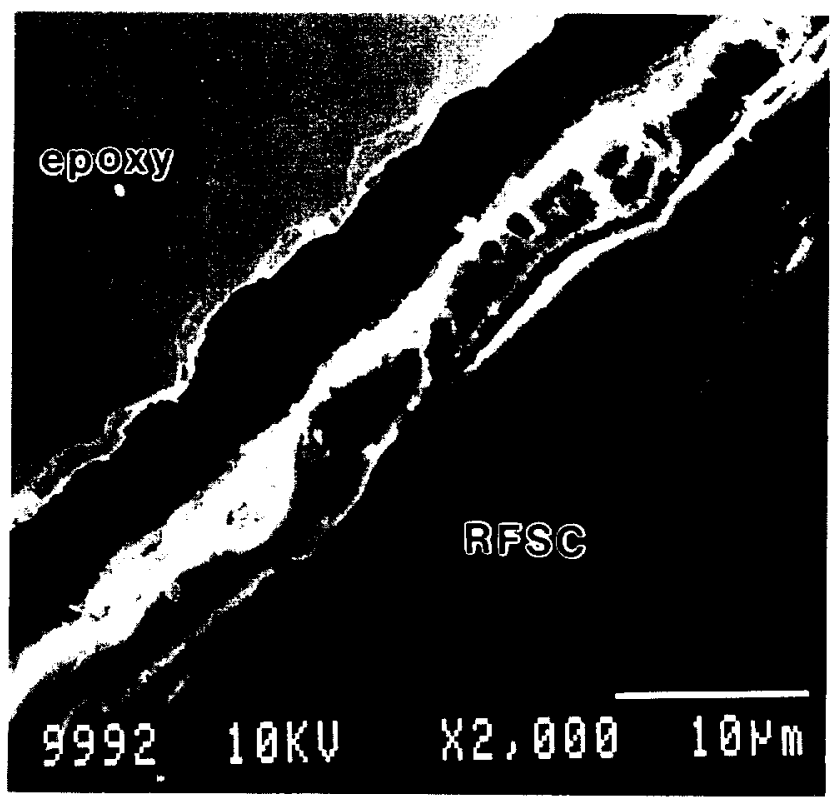

(a)

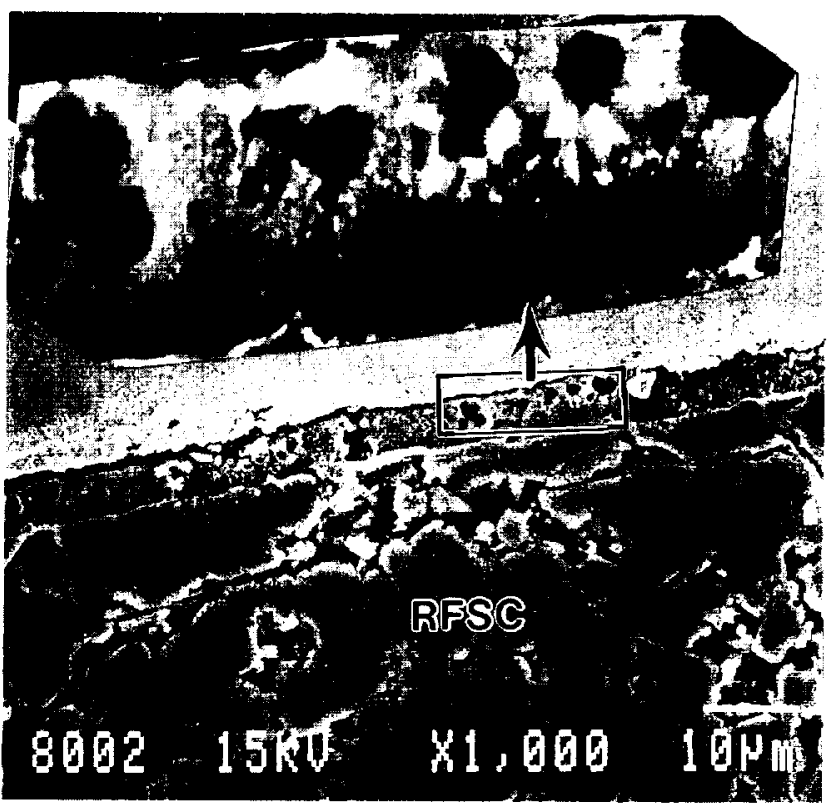

(b)

FIG. 3. SEM micrographs of RFSC ( $\left.\mathrm{MoSi}_{2}\right)$, oxidized at 1.350$)^{\circ} \mathrm{C}$. As in the basic RFSC (Fig. 2), some minor pockets of the substrate remained pore-free (a). while most of it hecame extensively porous beneath the scale (b). The inset enlargement in (b) shows that the oxide 100 is highly porous.

was greatest around $1250{ }^{\circ} \mathrm{C}$ and decreased thereafter with increasing temperature. In some cases, as Fig. 2(a) shows, porosity was severe enough to cause cavitation of the substrate. But, as Fig. 2(b) and 3(b) show, there were areas where the materials remained largely free of porosity even after oxidation. The oxide scale itself was 
porous in most cases, the porosity increasing markedly with oxidation temperature. In Fig. 3(a) this is illustrated with a higher-magnification inset of the oxide scale.

\section{B. Weight change profiles}

Figure 4 shows the change of specific sample weight as a function of time for both varieties of RFSC. (For clarity, only a representative sampling of the results is shown in Fig. 4: for temperatures near the low and high extremities of the investigated range.) The oxidation behavior was characterized by an initial loss of weight, followed by weight gain. For both materials, weight loss was dominant at lower temperatures.

The extent of weight loss (as reflected in the lowest weight registered by each sample) decreased with temperature, substantially so in the case of the material with $\mathrm{MoSi}_{2}$. There was a variability in the magnitude (and, to a lesser extent, duration) of weight loss among the samples and between temperatures, as may be seen in Fig. 4. Greater consistency was observed in the total weight grain for each sample, which increased monotonically from about $0.1 \mathrm{mg} / \mathrm{cm}^{2}$ at the lowest temperature to about $0.35 \mathrm{mg} / \mathrm{cm}^{2}$ at the highest. While porosity (from the removal of carbon) was observed at depths up to $70 \mu \mathrm{m}$, it was mostly limited to $\sim 30-40 \mu \mathrm{m}$ beneath the oxide. Using an average depth of $35 \mu \mathrm{m}$ for the porous band, a sample surface areas of $-10 \mathrm{~cm}^{2}$ per side, and a 5-10 vol \% of residual glassy carbon (with a density of $1.5 \mathrm{gm} / \mathrm{cm}^{3}$ ), the total weight loss from complete oxidation of all the carbon to a depth of $35 \mu \mathrm{m}$ on both faces of a sample would be $0.5-1.0 \mathrm{mg} / \mathrm{cm}^{3}$. This agrees well with the magnitude of weight losses reflected in Figs. 4(a)-4(c).

\section{Kinetics}

The plots of weight change are shown in Fig. 4(a) for the basic RFSC material, and in 4(b) for the variety with $\mathrm{MoSi}_{2}$. Overall, gross trends in the oxidation kinetics were parabolic at all temperatures, in the weightgain regime, so that for each sample it was possible to determine an overall parabolic rate constant $\left(k_{p}\right)$ with a good regression fit $\left(R^{2}>0.9\right)$. This is shown in Fig. 4(c) for the variety with $\mathrm{MoSi}_{2}$. However, most samples exhibited discernible negative departures from exact parabolic behavior. This was evident, in some cases, in a flattening of the parabolic plots (of specific

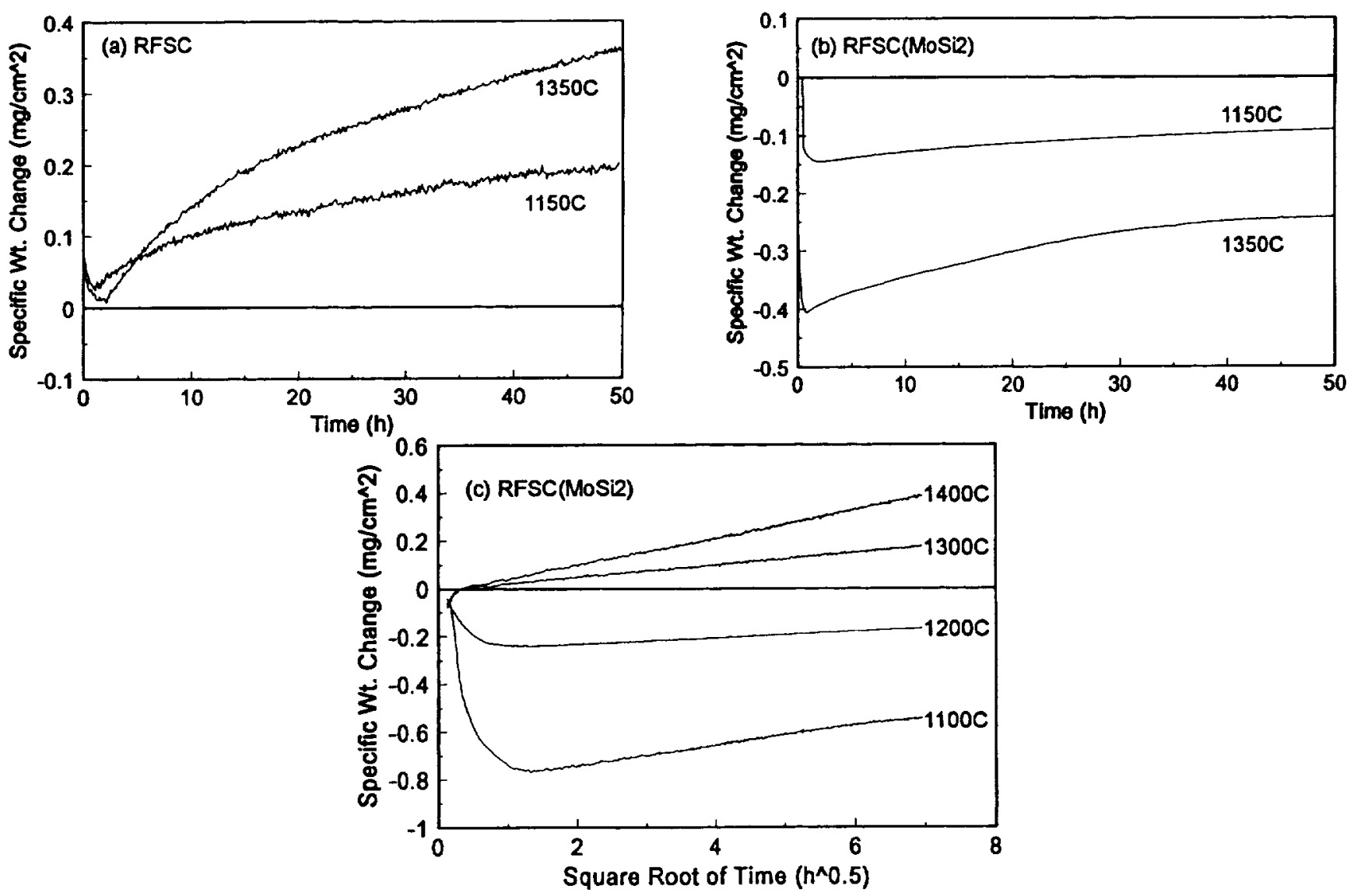

FIG. 4. (a,b) Weight gain plots at high and low temperatures for the two varieties of RFSC illustrating initial weight loss and subsequent weight gain; (c) parabolic plot for the Mo-containing variety. 
weight change against the square root of time) at long times. Stronger evidence of this deviation may be seen in Fig. 5. Figure 5(a) presents the parabolic plot for the basic RFSC material at three temperatures, omitting data from the initial weight loss regime. Regression yielded the parabolic rate constants and correlation factors indicated in the table inset in the figure. Thus, the oxidation kinetics in each case seems to be reasonably parabolic. Nevertheless, when the same data is replotted as log of specific weight gain versus log of time, shown in Fig. 5(b), the scale growth exponents derived by regression range from 0.38 to 0.43 (with standard deviations of $0.002-0.003)$, thus departing significantly from the 0.50 characteristic of parabolic oxidation.

Most runs were repeated (becaluse of the inconsistency in the extent of initial weight loss). The (wo $k_{p}$ values calculated from repeat runs for each material differed by up to a factor of 2.5 at the lower temperatures (where the oxide coverage was sparse

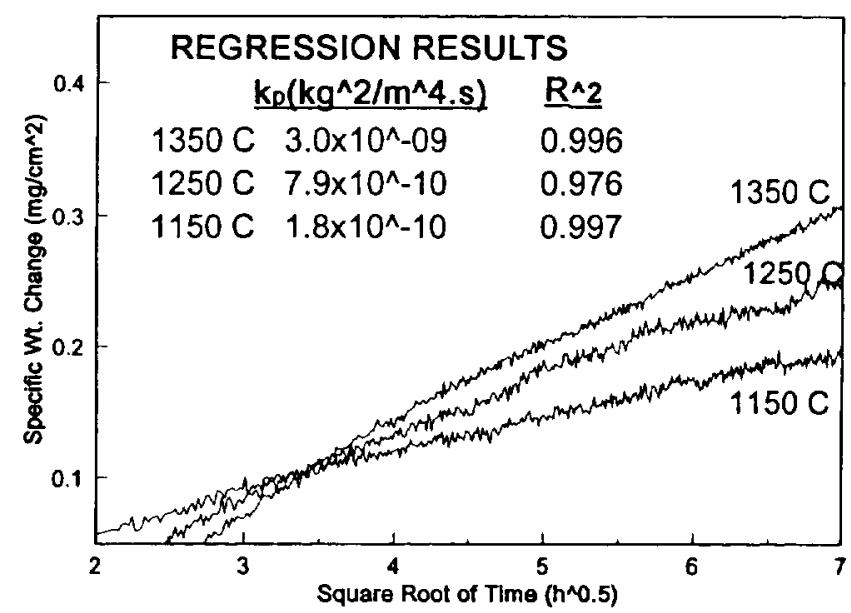

(a)

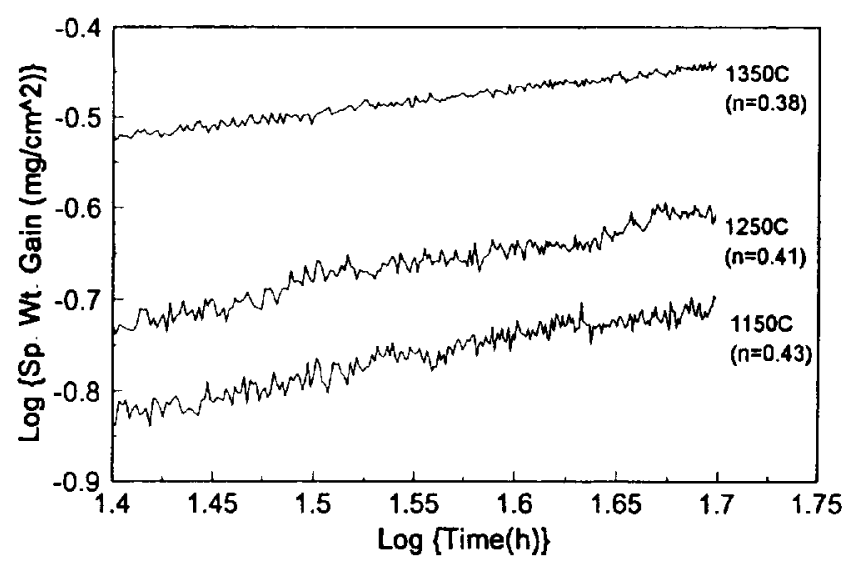

(b)

Fig. 5. Comparison of the parabolic plot (a) and logarithmic plot (b) for the oxidation of batsic RFSC. The latter plot demonstrates that the kinetics were not truly parabolic. despite appearances in the former. to spotty), but were in much better agreement at the higher temperatures.

Passive oxidation behavior was fully developed rather early in each run, as may be seen in Figs. 4(c) or 5(a). Therefore, the oxide scale thickness on each sample upon withdrawal from the furnace should provide a reliable check of the rate constant, $k_{p}$, determined from the TGA curve. The total oxide thickness after a given time, $t$, is $x=\left(K_{p} \cdot t\right)^{1 / 2}$; here $K_{p}$ has dimensions of distance ${ }^{2} /$ time and may be derived from the thermogravimetric $k_{p}$, which has units of mass ${ }^{2} /$ (distance $^{t} \cdot$ time). The volume-to-mass conversion factor for the complete oxidation of $\mathrm{SiC}$ to $\mathrm{CO}$ and $\mathrm{SiO}_{2}$ (defined by Luthra' ${ }^{14}$ as the mass gain per unit volume of oxidation product) is $6 \times 10^{h}$. Hence, our $k_{b}$, units of $\mathrm{kg}^{2} / \mathrm{m}^{+} \cdot \mathrm{s}$ in Fig. 5(a) may be converted to the oxidethickening $K_{p}$, units of $\mu \mathrm{m}^{2} / \mathrm{h}$ by multiplying with a factor of $6.03 \times 10^{9}$. Thus, a predicted oxide thickness was calculated for each run from the TGA data for comparison with the actual oxide thickness measured by SEM of the sample cross section. This results was averaged for two runs per sample at a given temperature. Figure 6 compares the measured and predicted oxide thickness on this material as a function of oxidation temperature. The ratio of those thicknesses appears at the bottom of the figure. It varies within the very narrow range of about 0.5 to 0.6 , indicating that nearly half the oxide formed is not to be found on the surface of the samples.

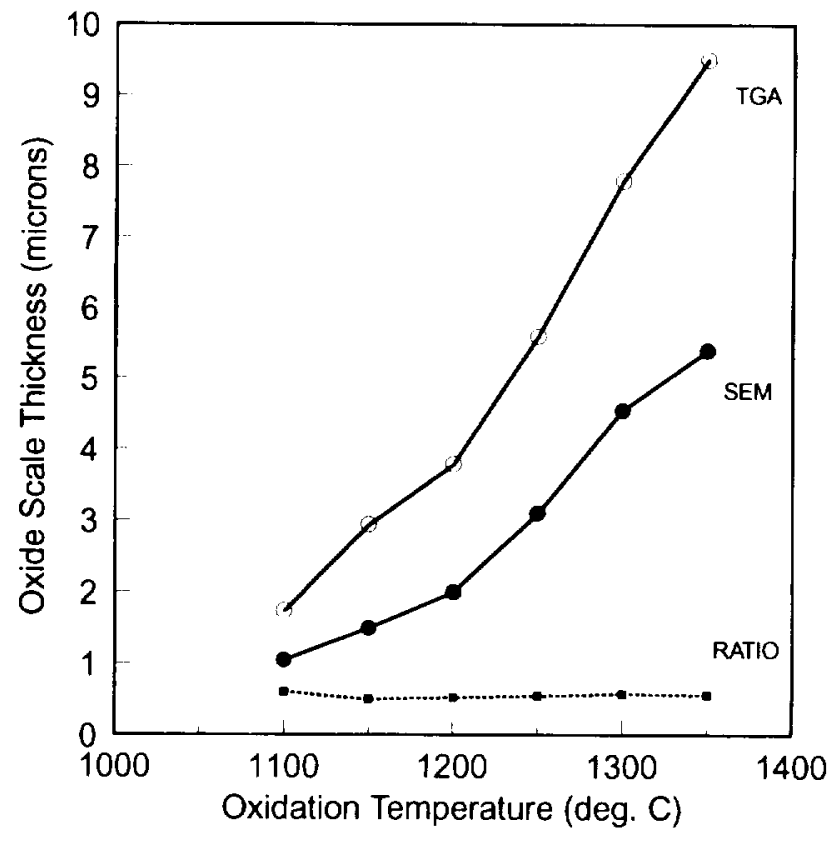

FIG. 6. Comparison of oxide thickness measured by SEM and that calculated from TGA datia. The $50 \%$ disparity between the two thicknesses is due to extensive internal oxidation. 


\section{Activation enthalpies}

Figure 7 shows the Arrhenius plots of the $k_{l}$, values as a function of inverse temperature. The difference in oxidation kinetics between the two varieties of RFSC was more significant than the scatter between repeats at each temperature. Figure 7(a) shows that the parabolic constants were higher by about an order of magnitude for the variety with $\mathrm{MoSi}_{2}$. Figure 7(b) shows the activation enthalpies for the oxidation of these materials, derived from the slopes in Fig. 7(a). They are compared with literature values for other varieties of polycrystalline $\mathrm{SiC}$ [including additive-densified and chemical-vapordeposited (CVD) materials], as well as for silicon.

As may be expected, our $k_{p}$, values for RFSC are higher by about two orders of magnitude than comparable values for CVD-SiC. However, they compare well with the other densified $\mathrm{SiC}$ materials, lying slightly above the corresponding results for hot-pressed (HP) $\mathrm{SiC}$, but up to an order of magnitude below those for continuously nucleated thermally deposited (CNTD) $\mathrm{SiC}$. The enthalpies are very similar for both varieties of RFSC, being $114 \mathrm{~kJ} / \mathrm{mol}$ for the $\mathrm{MoSi}_{2}$-free sample and $129 \mathrm{~kJ} / \mathrm{mol}$ for the sample with $\mathrm{MoSi}_{2}$. It is evident from Fig. 7(b) that the activation enthalpy for the oxidation of RFSC is in very good agreement with the value of $118 \mathrm{~kJ} / \mathrm{mol}$ reported for CVD-SiC ${ }^{15}$ at the bottom of the figure. The expected enthalpy for the formation of silica by the oxidation of $\mathrm{Si}$ or $\mathrm{SiC}$ is $118 \mathrm{~kJ} / \mathrm{mol}^{16}$

\section{E. Oxidation product}

The sole oxidation product determined by XRD was $\mathrm{SiO}_{2}$ : mainly $\alpha$-cristobalite, but with a significant amount of tridymite. The intensity of the tridymite signal was highest at the lowest temperatures, and diminished with increasing temperatures, being barely detectable at $1250{ }^{\circ} \mathrm{C}$. The tridymite signal was always stronger in the RFSC material containing $\mathrm{MoSi}_{2}$ than in the basic RFSC: the oxide on the latter material was essentially cristobalite above $1150{ }^{\circ} \mathrm{C}$. In the material with $\mathrm{MoSi}_{2}$, XRD also detected $\mathrm{MoSi}_{2}$ and $\mathrm{Si}$ below $1300^{\circ} \mathrm{C}$, as well as $\mathrm{SiC}$ at lower oxidation temperatures. However, no oxide or suboxide of molybdenum was detected.

Surprisingly, amorphous silica was not detected on any sample at any temperature. Figure 8 compares oxide scales on the two materials. Figure 8(a) shows the surface of a sample with $\mathrm{MoSi}_{2}$ oxidized for $50 \mathrm{~h}$ at $1200^{\circ} \mathrm{C}$. This oxide scale was about $2 \mu \mathrm{m}$ thick, and there was no indication of amorphous silica in the XRD spectrum. Thus, even at this temperature the oxide scale appears to be crystalline. SEM-EDS analysis of this oxide yielded Mo and Si signals (assumed to be from $\mathrm{MoSi}_{2}$ ) from the dark blotches. Some Si was detected in the oxide of the basic RFSC material at $1150{ }^{\circ} \mathrm{C}$ and (especially) $1100^{\circ} \mathrm{C}$, indicating a thin or spotty oxide

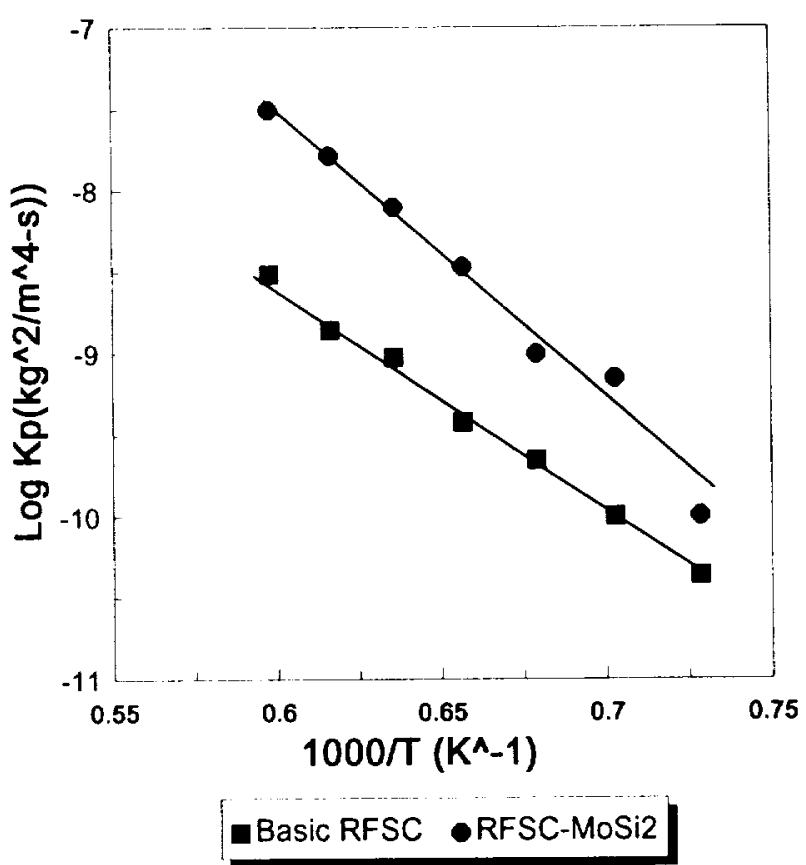

(a)

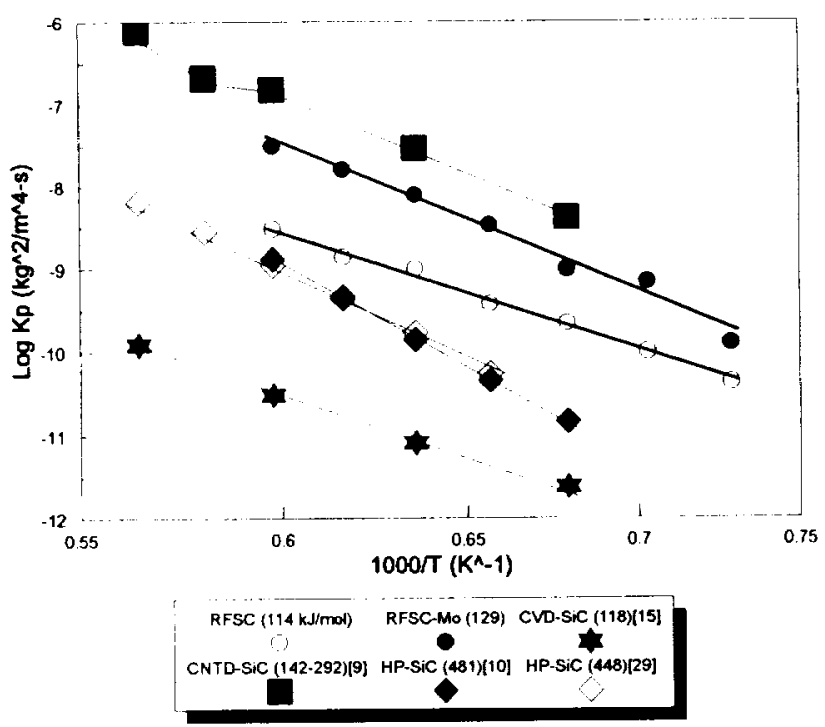

(b)

FIG. 7. Arrhenius plots of oxidation kinetics versus inverse temperature: (a) for the two varieties of RFSC ceramics, and (b) comparing the activation energies for the oxidation of selected silica formers. The information comes from references shown in brackets | 1 .

coverage, but not at $1250{ }^{\circ} \mathrm{C}$ or above. Figure $8(b)$ is from the basic RFSC sample oxidized at $1300{ }^{\circ} \mathrm{C}$. This oxide scale was apparently fully crystallized, also, but exhibited no second phases. In both RFSC materials, the oxide film was too thin at $1100^{\circ} \mathrm{C}$ and $1150{ }^{\circ} \mathrm{C}$ for its state of crystallinity to be ascertained with confidence, but its changing appearance with polarization under the light microscope indicated that it was crystalline. 

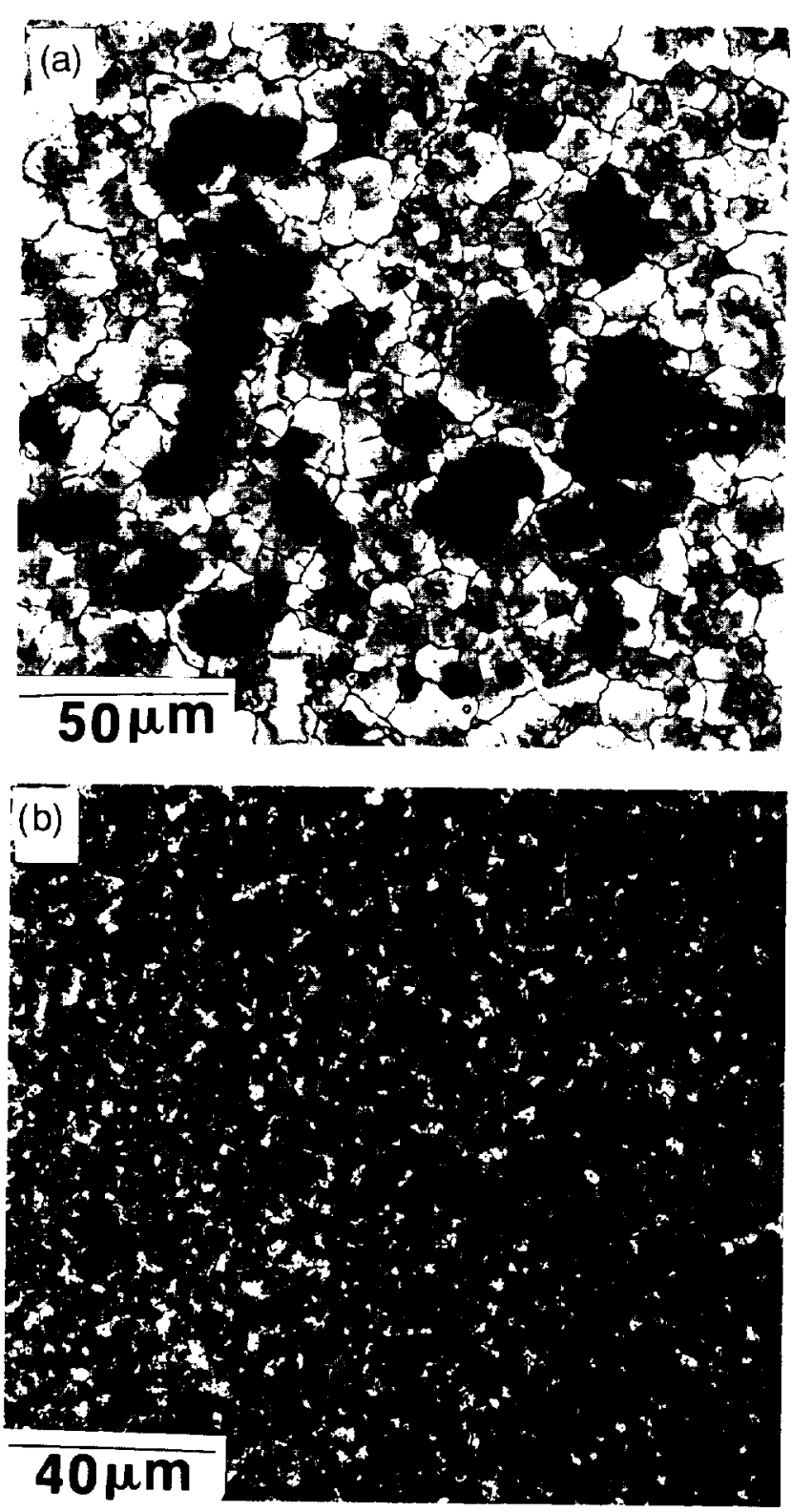

FIG. 8. Light micrographs of oxide scales on (a) RFSC with MoSiz, at $1200^{\circ} \mathrm{C}$; and (b) hasic RFSC at $1.3000^{\circ} \mathrm{C}$.

\section{DISCUSSION}

\section{A. The effect of second phases and impurities}

At the temperatures of these experiments, Si oxidizes to $\mathrm{SiO}_{2}(\mathrm{~s}), \mathrm{MoSi}_{2}$ to $\mathrm{SiO}_{2}(\mathrm{~s})+\mathrm{MoO}_{3}(\mathrm{~g})$, and $\mathrm{SiC}$ to $\mathrm{SiO}_{2}(s)+\mathrm{CO}(g)$. In each of these cases the result is a net gain in weight arising from the solid silica scale that forms. The initial weight loss in our samples indicates that the loss of volatiles dominates the oxidation process at the early stage. This can come only from carbon. Of all the constituents in these RFSC materials, carbon is the only one whose oxidation leaves behind no solid product, and the measured weight losses are in good agreement with the total weight of carbon contained in the oxidation-affected zone. The shallower weight loss and the less enhanced $k_{n}$, values exhibited by the RFSC variety without $\mathrm{MoSi}_{2}$ may be a reflection of a somewhat better product homogenization during the conversion, since the infiltration reaction is expected to be simpler in a one-component melt than in one with alloying additives.

The fact that the measured oxide thicknesses on the samples are only about $50 \%$ of the value predicted from the TGA data is a strong indication of internal oxidation in these materials. The effect is as if the oxide scale is spread over a total surface area that is actually double the external surface area used in the TGA calculations, thus halving its thickness. This is supported by the significant porosity exposed by polishing oxidized samples. Since the as-fabricated material is of near-theoretical density, the porosity that appears after oxidation must form when the oxidant fingers down the network of residual carbon and silicon. The carbon is cleaned out ahead of the main oxidation front which is associated with the external surface areas of the sample. The oxidation of carbon deep in the bulk probably occurs throughout each run. When it is outpaced by the formation of $\mathrm{SiO}_{2}$ from the oxidation of the other constituents, the sample begins to gain weight and the oxidation kinetics become predominantly parabolic. Nevertheless, the generation of copious amounts of $\mathrm{CO}$ gas by internal oxidation continues, as is evident in the porosity in our oxide scales.

The $k_{p}$, values for the RFSC materials exceed those for hot-pressed and pressureless-sintered silicon carbide by at least one order of magnitude. These high oxidation rates indicate that some factor other than the oxidation of $\mathrm{SiC}$ may be contributing to the overatl process. It is difficult to identify all the contributory factors merely from the weight-gain data. One probable factor is internal oxidation, which greatly increases the surface area of the sample available for reaction with the oxidant. Another important factor is the oxidation of residual Si. which constitutes a significant fraction of our RFSC. The $k_{n}$ value for the oxidation of $\mathrm{Si}$ exceeds that of $\mathrm{SiC}$ at the same temperatures by a factor that has been variously reported as 2 to 5.9.17-? Since the two materials have identical oxidation enthalpies (ideally), the effect of a significant contribution from the oxidation of residual $\mathrm{Si}$ would be a large increase in $k_{p}$, but with no charge in the activation energy, which is precisely the result we observed. As may be seen in Fig. 7(b), the oxidation kinetics and enthalpy of RFSC most resemble those of CNTD-SiC, among the varieties of densified silicon carbide ceramics. This is probably because the two materials share two key microstructural features. Like RFSC, CNTD-SiC is fine-grained (with a grain size of 0.05 to $\left(0.1 \mu^{21}\right)$, and has a substantial content of free silicon.' 
Impurities may also have contributed to the enhanced oxidation rates of our materials. It is possible that the carbon precursor and/or the silicon introduced trace impurities. It has also been shown that impurities can vaporize from the sort of commercial, "high-purity" alumina furnace tubes used in this study and cause enhanced oxidation rates, to an extent that diminishes and eventually disappears with prolonged use of the tube. ${ }^{22}$ Impurities are known to reduce the viscosity of the oxide scale on silica formers, thus increasing the diffusivity of various species through the oxide. 10.11 .23 .24 This boosts oxidation rate in two ways. First, a silicate grain boundary phase in the oxide scale would accelerate the pipe diffusion of oxygen. Second, most impurities reduce the viscosity of the $\mathrm{SiO}_{2}$ network. This would also increase the diffusivity of the oxidant and of various species in the oxide scale.

\section{B. Deviation from parabolic kinetics}

The observed negative departure from parabolic behavior, on the other hand. indicates that there were also factors acting to slow down the oxidation kinetics in the passive regime. Such a retardation of passive oxidation is usually described as logarithmic kinetics. The general law of oxide scale growth during oxidation relates the change in the oxide thickness, $\Delta x$ (or change in the sample weight, $\Delta w$, as the case may be), to the elapsed oxidation time by the equation $\Delta x=t^{\prime \prime}$. An exponent of $n=1.0$ describes linear kinetics, 0.5 parabolic kinetics, and 0.5 to 1.0 paralinear kinetics. An exponent of $n>$ 0.5 is said to describe logarithmic kinetics since only a plot of $\log \Delta x$ against log of time yields a straight line in that case. Logarithmic oxidation is thought to set in when the oxide begins to crystallize because the steady decrease of the amorphous phase (which is the preferred path of oxidant permeation through the scale) amounts to a steady decrease of the effective oxidation cross section, thereby reducing the oxidation rate constant. ${ }^{24} 27$ It has been shown that the oxidation rates of various $\mathrm{SiC}$ materials become retarded when the oxide scale devitrities into spherulitic cristobalite. ${ }^{9.28}$ It is very likely, therefore, that the negative deviation from parabolic kinetics in our samples was a consequence of the proneness to early crystallization of the oxides. The connection will be explored elsewhere.

It should be mentioned here that very similar results have been reported for silicon nitride. Davidge et al. ${ }^{29}$ studied the oxidation behavior of reaction-sintered silicon nitride which contained about $21 \%$ porosity. They observed much internal oxidation, enhanced kinetics, and an oxide scale that was found to be cristobalite at all temperatures from $1000{ }^{\circ} \mathrm{C}$ to $1400{ }^{\circ} \mathrm{C}$, and they described the kinetics as parabolic at all temperatures. It is interesting that they also observed the same decrease of the parabolic rates with oxidation time. Their plots of sample weight gain versus the square root of time yielded curves that clearly declined with increasing time. The declination may be viewed as either continuous or segmented. Davidge et al. chose the later description, while in our case we have chosen the former interpretation. However, they did not connect this negative deviation with the observed proneness of the oxide to crystallinity. Instead they suggest that it was caused by a change from a stage of predominantly internal oxidation to one of external oxidation, although they did not propose a mechanism for such an effect. Otherwise, our results are in total agreement with theirs.

Very similar behavior has also been reported in more recent times for the oxidation of CVD-SiC at high temperatures. Narushima et al $^{30}$ reported that a plot of the square of weight gain versus the oxidation time yielded curves, rather than straight lines, at all temperatures from $1550{ }^{\circ} \mathrm{C}$ to $1675^{\circ} \mathrm{C}$. Like Davidge et al., they interpreted their data as indicated two different $k_{p}$, regimes (rather than a continuous decrease in $k_{p}$ values). However, as in the present case, they attribute the changing $k_{p}$ values to the crystallization of the oxide scale on the sample.

The strong tendency to oxide crystallinity itself might be caused by a variety of factors. One, as we have seen, is that impurities can reduce the viscosity, thus lowering the glass transition temperature, $t_{g}$, of the oxide. Another is the fine microstructure of our RFSC. The devitrification of the oxide scale proceeds by the nucleation of cristobalite spherulites, ${ }^{28,31}$ and this is facilitated by the presence of suitable nucleation sites, such as asperities and topological features on the oxidizing surface of the substrate, ${ }^{9.29}$ and the density of such sites increases as the substrate grain size decreases."

\section{SUMMARY AND CONCLUSIONS}

The oxidation behavior of RFSC presents an uncommon mix of factors. At least five of those factors have been identified in this paper: initial weight loss (and possibly continued loss of volatile second phase contents in the passive regime), internal oxidation, enhanced oxidation kinetics (but with a normal oxidation en(halpy), negative deviation from parabolic kinetics in the passive regime, and a strong tendency to oxide crystallinity at nearly all temperatures investigated. The net result is that oxidation is initially rapid and the $k_{p}$ values significantly elevated in the passive regime, but the kinctics also slow down noticeably with progress of passive oxidation as logarithmic kinetics set in. The presence of residual carbon and silicon is probably responsible for many of these factors, particularly those that enhance the oxidation rate; while the possibility of some trace impurities and, above all, 
the fine microstructure of the RFSC may account for the oxide crystallinity.

\section{ACKNOWLEDGMENT}

We are grateful to Don L. Humphrey of NYMA, Inc. for the TGA runs.

\section{REFERENCES}

1. D.C. Larsen. J. Adams. L. Johnson. A. Teotia, and L. Hill. Coramic Matcrials for Heat Engines ( Noyes Publications, Park Ridge, NJ, 19851.

2. M. Singh and S. R. Levine. "Low wost fabrication of silicon car hide based ceramics and fiber reinfored composites." Technology 20)4. Washington, DC (1994).

3. C.W. Forrest. P. Kennedy, and J. V. Shennan. Proc, 5th Simp on Sperial Coramies (The British Ceramic Rescarch Association. Stoke-on-Trent, U.K.. 1972. pp. 99-123.

4. M. Singh and D. R. Behrendt. NASA-TM-105860) (1992).

5. M. Singh and D. R. Behrendt. J. Mater. Res, 9. 1701-1708 (1994)

6. M. Singh and D. R. Behrendt. Matter. Sci. Engg, A187, 103-107 (1994).

7. M. Singh and D. R. Behrendt, Mater. Sci. Engg. A 194. 19.3-2(x) (1905).

8. M. Singh. R. Pawlik. J. A. Salem, and D. R. Behrendt. Ceramic Trans. Vol. 38. Adrances in Coramic Matrix Composites, edited by N.P. Binnsal (The American Ceramic Society. Westerville. OH. 1993), pp. 349-360)

9. J.A. Costello and R.E. Tressler, J. Am. Ceram. Soc, 69 (9). $674-681(1986)$.

10. S.C. Singhal, J. Mater. Sci. 11, 1246-1253 (1976).

II. P. Andrews and F. Riley, J. Eur. (eram. Soc. 7, 125-1.32 (1991).

12. D. R. Clarke and F.F. I ange. J. Am. Ceram. Soc, 63 (9-10), $586-593(1980)$.

13. D. M. Mieskowski, T. E. Mitchell, and A. H. Heuer, J. Am. Ceram. Soc. $67(1) . C 17-18(1984)$.
14. K. L. Luthra, J. Am. Ceram. Soc. 74 (5), 1095-1103 11991).

15. 1. U. Ogbuji and E.J. Opilia. J. Electrochem. Soc. 142 (3) $925-930$ (1995).

16. B. F. Deal and A. S. Grove. J. Appl. Phys. 36 (12), 3770-3778 (1965).

17. G.H. Schiroky. R.J. Price, and J.E. Sheehan, "Oxidation Characteristics of $\mathrm{CVD} \mathrm{SiC}$ and $\mathrm{Si}_{3} \mathrm{~N}_{4}, "$ GA Project 3799. December 1986.

18. K. Molzfelt. Acta Chem. Scand. 18 (7), 1596-1606 (1964).

19. L. Filipurzi, R. Naslain, and C Jalussaud. J. Mater. Sci. 27. $3330-33.34(1992)$.

20. 7. Zheng, R. E. Tressler, and K. E. Spear. J. Electrochem. Soc. $137(3), 854-858(199))$.

21. J. J. Stiglich, D. G. Bltat, and R. A. Holrl, Ceram. Int 6 (1), 3-10 (1980).

22. E. J. Opila. J. Am. Ceram. Soc. 78 (4). 1107-1110 (1995).

23. M. A. Lamkin. F. L. Riley, and J. Fordham, J. Eur. Ceram. Sox. 10. $347-367(1902)$.

24. D. E. Davies, L. R. Evans, and J. N. Agar, Proc. Soc. 225A. $443-462(1954)$.

25. J. Persson. P. Kall, and M. Nygren, J. Am. Ceram. Six: 75 (12). $3377-3384$ (1992).

26. J. Persson. P. Kall, and M. Nygren, J. Eur. Ceram. Sox. 12. $177-184(1993)$.

27. K. G. Nickel in Corrosion of Adranced Cormics: Measurement and Modelling. edited by K. G. Nickel (Kluwer Academic Publishers, Boston, 1994), pp. 59-71.

28. L. U. Ogbuji. J. Mater. Sci. 16. $2753-2759$ (1981).

29. R. W. Davidge. A.G. Evans, D. Gilling. and P. R. Wilyman, in Special Ceramics 5 , edited by P. Popper (Ceorge Falkner Press, The British Ceramic Research Association. Stoke-on-Trent. L.K. 1972), pp. 329-343

30. T. Narushima, T. Goto, and T. Hirai, J. Am. Ceram. Soc, $72(8)$. $1386-1390(1989)$.

31. A. H. Heuer, L.. U. Oghuji, and T. F. Mitchell, J. Am. Ceram Soc. $6.3(5-6) .354-355(1080)$. 
